\title{
DEVELOPMENT AND VALIDATION OF SPECTROPHOTOMETRIC METHODS FOR SIMULTANEOUS ESTIMATION OF VILANTEROL AND FLUTICASONE FUROATE IN PHARMACEUTICAL FORMULATIONS
}

\author{
SIVA KISHORE MASIMUKKU ${ }^{1}$, RAMBABU CHINTALA ${ }^{2 *}$ \\ ${ }^{1}$ Department of Chemistry, K.B.N. P.G. College, Vijayawada, Andhra Pradesh, India. ${ }^{2}$ Department of Chemistry, Acharya Nagarjuna \\ University, Guntur, Andhra Pradesh, India. Email: siva.kishore@rediff mail.com
}

Received: 23 December 2016, Revised and Accepted: 31 January 2017

\section{ABSTRACT}

Objective: To develop a simple, rapid, precise, accurate, sensitive spectrophotometric methods (A and B) were developed for simultaneous estimation and validation of vilanterol (VTL) and fluticasone furoate (FFE) in pure and tablet dosage forms.

Methods: Method A is a simultaneous equation method and Method B is a first-order derivative spectrophotometric method. Pure drug samples of VTL and FFE were dissolved in a mixture of methanol and ethanol in the ratio of 1:1 (v/v) and found to have absorbance maxima at $231 \mathrm{~nm}$ for VTL and $260 \mathrm{~nm}$ for FFE, respectively.

Results: The linearity lies between $2.5-10 \mu \mathrm{g} / \mathrm{ml}$ for VTL and 10-60 $\mu \mathrm{g} / \mathrm{ml}$ for FFE in these two methods (A and B). The correlation coefficient ( $\mathrm{r}^{2}$ ) was found to be 0.999 for both VTL and FFE, the limit of detection and limit of quantification were found to be 0.015 and $0.05 \mu \mathrm{g} / \mathrm{ml}$ for VTL and 0.05 and $0.2 \mu \mathrm{g} / \mathrm{ml}$ for FFE, respectively. The results of analysis have been validated statistically by recovery studies as per International Conference on Harmonization guidelines.

Conclusion: The two methods A and B showed good reproducibility and recovery with \%RSD $<2$. Hence, both methods were found to be rapid, specific, precise, and accurate and can be successfully applied for the routine analysis of VTL and FFE in pure and combined dosage form.

Keywords: Fluticasone furoate, Vilanterol, Derivative spectrophotometric, Simultaneous equation method, Method development and validation.

(c) 2017 The Authors. Published by Innovare Academic Sciences Pvt Ltd. This is an open access article under the CC BY license (http://creativecommons. org/licenses/by/4. 0/) DOI: http://dx.doi.org/10.22159/ajpcr.2017.v10i4.16748

\section{INTRODUCTION}

Fluticasone furoate (FFE) $[(6 \alpha, 11 \beta, 16 \alpha, 17 \alpha)-6,9$-difluoro-17-\{[(fluoromethyl)thio]carbonyl\}-11-hydroxy-16-methyl-3-oxoandrosta-1,4dien-17-yl 2-furancarboxylate] and vilanterol (VTL)[4-\{(1R)-2-[(6$\{2$-[(2,6-Dichlorobenzyl)oxy]ethoxy\}hexyl)amino]-1-hydroxyethyl\}-2 hydroxymethyl)phenol] are available in a combined dosage form (trade names BreoEllipta and RelvarEllipta) approved by USFDA in 2013 used for the treatment of chronic obstructive pulmonary disease (COPD), including chronic bronchitis and emphysema and asthma [1]. FFE is a synthetic trifluorinated corticosteroid with potent anti-inflammatory activity used for long-term maintenance treatment of airflow obstruction in patients with COPD, including chronic bronchitis and emphysema [2]. It is also approved for the treatment of asthma [3,4], nasal allergy symptoms, including congestion, sneezing, itching, and runny nose. It works by reducing inflammatory reactions in the nasal airway in response to allergens and irritants in the air. VTL is a selective long-acting beta2-adrenergic agonist used for once daily treatment of COPD and asthma $[5,6]$. Literature survey revealed that there is only a single ultra-performance liquid chromatography method developed for determination of FFE and benzalkonium chloride [7]. Since no spectrophotometric method is reported for simultaneous estimation, the present study is aimed to develop two spectrophotometric methods, i.e., first-order derivative spectrophotometric and simultaneous equation method for simultaneous estimation of VTL and FFE in its pharmaceutical formulations.

\section{METHODS}

Chemicals and materials

Analytically pure FFE and VTL were obtained as gift samples from reputed pharmaceutical companies. Methanol, (Merck, Mumbai, India) water was of HPLC grade, while ethanol used for the preparation of mobile phase was of analytical grade (Merck Specialties Private Limited, Mumbai, India). Formulations of BreoEllipta inhalation powder contains a combination of fluticasone and VTL containing labeled amount of fluticasone $100 \mu \mathrm{g}$-VTL $25 \mu \mathrm{g}$ were procured from the local market.

\section{Equipment}

A double beam ultraviolet (UV)/visible spectrophotometer model Tec comp UV-2301 was used to carry out spectral analysis and the data were recorded by Hitachi software. Standard and sample drugs were weighed by using Denver electronic analytical balance (SI-234). A Synchronies C-18 $(250 \mathrm{~mm} \times 4.6 \mathrm{~mm}, 5 \mu \mathrm{m})$ column was used as a stationary phase.

\section{Preparation of standard drug solution}

Amount of $10 \mathrm{mg}$ of standard drug VTL and FFE were weighed separately and dissolved in $5 \mathrm{ml}$ diluent then transferred to a $10 \mathrm{ml}$ volumetric flask sonicate it for 5 minutes, finally volume was made up to the mark with same solvent to make $1000 \mu \mathrm{g} / \mathrm{ml}$ stock solution.

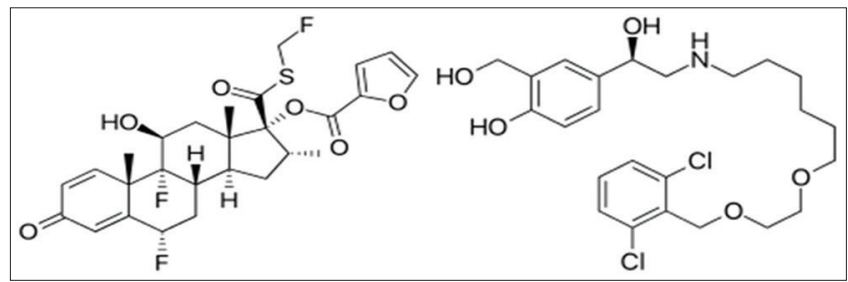

Fig. 1: Chemical structures of fluticasone furoate and vilanterol 
From this, $1 \mathrm{ml}$ was again diluted to $10 \mathrm{ml}$ to get a concentration of $10,000 \mu \mathrm{g} / \mathrm{ml}$ solution of VTL and FFE were obtained separately. From the solution, required concentrations were prepared separately, and then, $1 \mathrm{ml}$ from each of the solution was mixed to obtain a combined solution for the simultaneous estimation of VTL and FFE.

\section{Method A: Simultaneous equation method}

From the stock solution of $1000 \mu \mathrm{g} / \mathrm{ml}$, working standard solutions of drugs were prepared by appropriate dilution and were scanned in entire UV range to determine the absorbance max. VTL has maximum absorbance at $231 \mathrm{~nm}$ while FFE at $260 \mathrm{~nm}$ (Fig. 2). Standard solutions were prepared having concentration $2.5-15 \mu \mathrm{g} / \mathrm{ml}$ for VTL and $10-60 \mu \mathrm{g} / \mathrm{ml}$ for FFE. At the absorbance's of these standard solutions, calibration curves were plotted at these wavelengths. Two simultaneous were formed using these absorptivity coefficient values [8,9].

$C_{x}=A_{2} a_{y 1}-A_{1} a_{y 2} / a_{x 2} a_{y 1}-a_{x 1} a_{y 2}$

$C_{y}=A_{1} a_{x 2}-A_{2} a_{x 1} / a_{x 2} a_{y 1}-a_{x 1} a_{y 2}$

Where,

$\mathrm{a}_{\mathrm{x} 1}=$ Absorptivity of VTL at $231 \mathrm{~nm}$

$\mathrm{a}_{\mathrm{x} 2}=$ Absorptivity of VTL at $260 \mathrm{~nm}$

$\mathrm{a}_{\mathrm{y} 1}=$ Absorptivity of FFE at $260 \mathrm{~nm}$

$\mathrm{a}_{\mathrm{y} 2}=$ Absorptivity of FFE at $231 \mathrm{~nm}$
$\mathrm{A}_{1}$ and $\mathrm{A}_{2}$ are the absorbance of the diluted sample at $231 \mathrm{~nm}$ and $260 \mathrm{~nm}$ respectively.

\section{Method B: First-order derivative spectrophotometric method}

The absorption spectra thus obtained by working standard solutions of VTL and FFE in the wavelength range of 200-400 nm against solvent methanol and ethanol in the ratio of $1: 1(\mathrm{v} / \mathrm{v})$ as blank were derivatized from first order. From the overlay spectra of both the drugs (Fig. 3), wavelengths selected for quantitation were $231 \mathrm{~nm}$ was used for VTL and $260 \mathrm{~nm}$ was used for FFE. The proposed method was validated according to the United States Pharmacopeia and International Conference on Harmonization guidelines [10-12] in terms of linearity and range, precision, accuracy.

\section{RESULTS AND DISCUSSION}

\section{Method A: Simultaneous equation method}

Study of overlain spectra shows that VTL has maximum absorbance at $231 \mathrm{~nm}$ while FFE at $260 \mathrm{~nm}$, respectively. The linearity with absorbance in the range $2.5-15 \mu \mathrm{g} / \mathrm{ml}$ for VTL and $10-60 \mu \mathrm{g} / \mathrm{ml}$ for FFE at their respective maxima was validated by least square method. Linearity results were presented in Table 1; calibration graphs were presented in Fig. 4. The accuracy of the method was determined by calculating mean percentage recovery. It was determined at 50,100 and $150 \%$ level. The percentage recovery ranges from 98.5 to 99.2 for VTL and 98.22-99.70

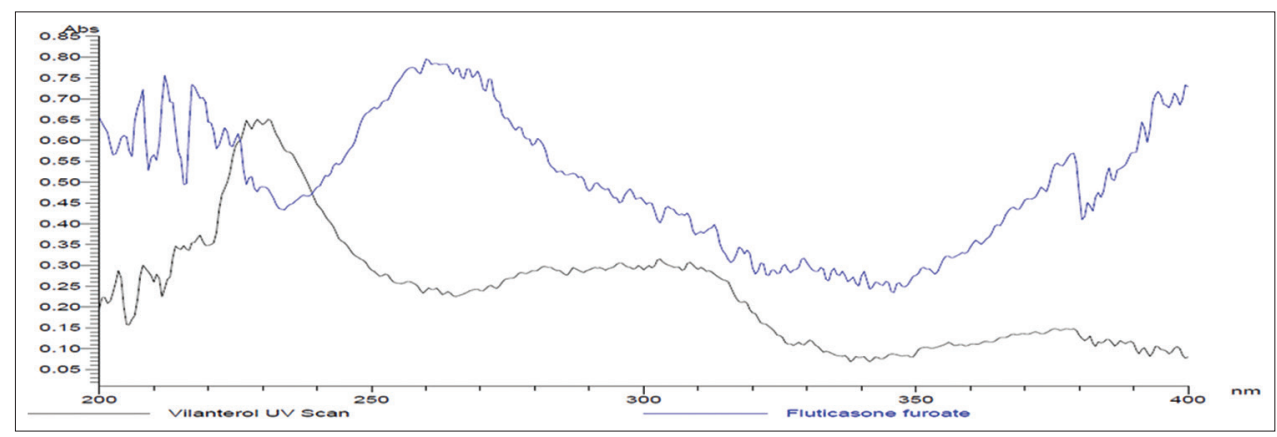

Fig. 2: Overlay spectra of vilanterol and fluticasone furoate

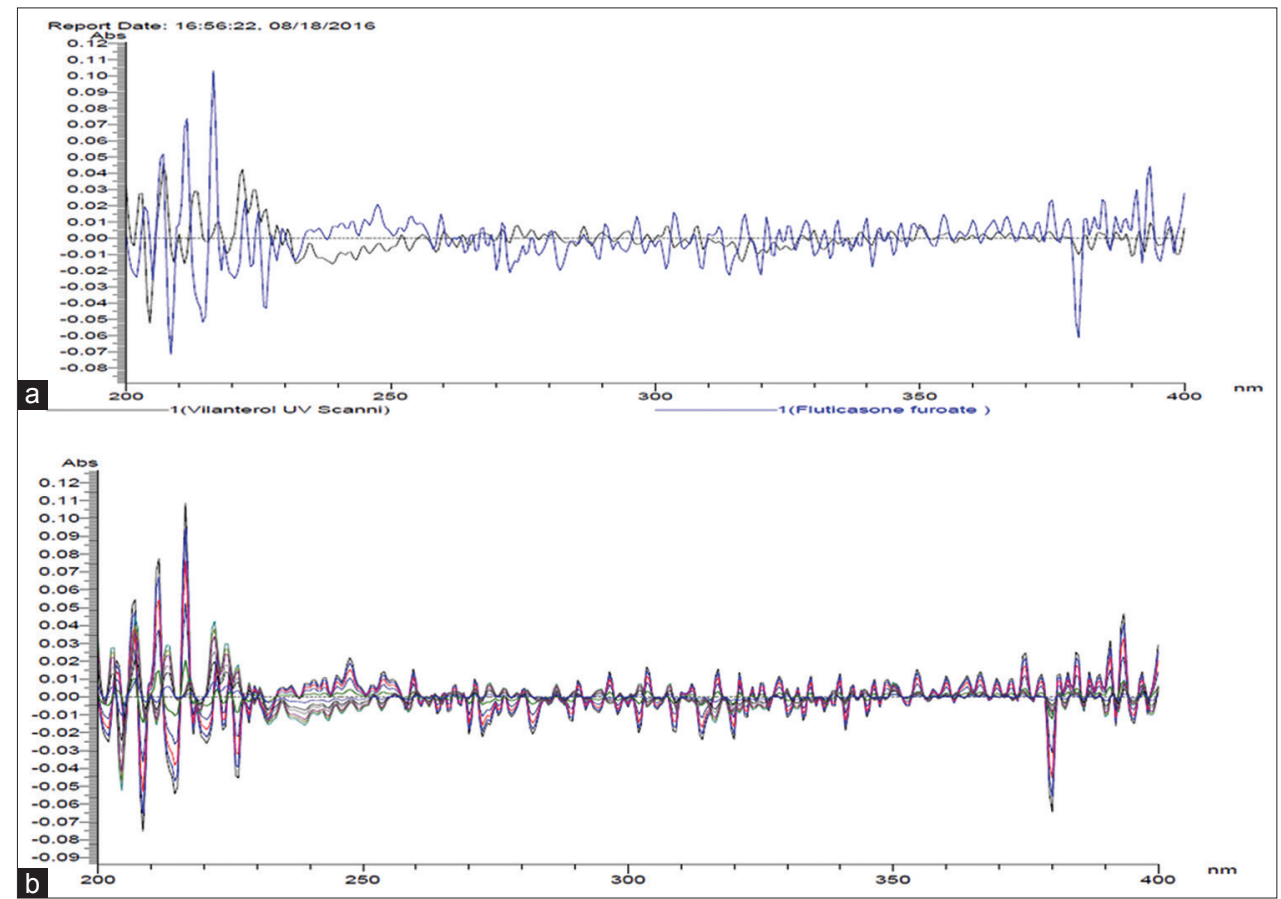

Fig. 3: ( $a$ and $b$ ) Overlay spectra of vilanterol and fluticasone furoate 
for FFE, respectively. Precision was calculated as repeatability $(\% \mathrm{RSD}<2)$ and inter and intraday variations $(\% \mathrm{RSD}<2)$ for both drugs. The proposed methods were found to be simple, accurate and rapid for the routine determination of VTL and FFE in tablet formulation.

Table 1: Results of linearity

\begin{tabular}{lllll}
\hline VTL & & & \\
\cline { 1 - 1 } Concentration & Absorbance & & Concentration & Absorbance \\
\hline 2.5 & $0.181 \pm 0.002$ & & 10 & $0.231 \pm 0.003$ \\
5 & $0.343 \pm 0.001$ & & 0 & $0.423 \pm 0.003$ \\
7.5 & $0.499 \pm 0.005$ & & 30 & $0.629 \pm 0.002$ \\
10 & $0.637 \pm 0.008$ & & 40 & $0.849 \pm 0.003$ \\
12.5 & $0.795 \pm 0.005$ & & 50 & $1.028 \pm 0.011$ \\
15 & $0.961 \pm 0.002$ & & 60 & $1.246 \pm 0.012$ \\
\hline
\end{tabular}

The values given in table are the average \pm standard deviation for three replicate measurements. VTL: Vilanterol, FFE: Fluticasone furoate
Marketed brand of the tablet was analyzed, and the amount of drug determined by proposed methods was found to be 99.07-98.62 for VTL and FFE, respectively (Table 2). The method can be successfully used for simultaneous estimation of VTL and FFE in combined dosage form.

\section{Method B: First-order derivative spectrophotometric method} Six points calibration curve were obtained in a concentration range from 2.5 to $15 \mu \mathrm{g} / \mathrm{ml}$ for VTL and $10-60 \mu \mathrm{g} / \mathrm{ml}$ for FFE, respectively. The response of the drug was found to be linear in the investigation concentration range and the linear regression equation was $\mathrm{y}=0.000245 \mathrm{x}$ -0.00047 with correlation coefficient $\left(\mathrm{r}^{2}\right) 0.999$ for VTL and $\mathrm{y}=8 \mathrm{E}-05 \mathrm{x}+$ 0.001 with correlation coefficient $\left(\mathrm{r}^{2}\right) 0.999$ for FFE (Table 3 and Fig. 5). The precision results were found to be within the limit where \%RSD values for VTL found to be $0.723,1.255$, and 0.626 for intraday, interday and ruggedness studies. And also \%RSD values for VTL found to be 0.411 , 0.22 and 0.26 for intraday, interday, and ruggedness studies. Recovery results also found within the validation limit that percentage of recovery are 98.6-100.24 for VTL and 99.55-100.75 for FFE, respectively.

Table 2: Formulation analysis VTL and FEE by proposed methods

\begin{tabular}{|c|c|c|c|c|c|c|}
\hline Method & Drug & $\begin{array}{l}\text { Brand } \\
\text { name }\end{array}$ & Labeled claim $\mu \mathrm{g} / \mathrm{ml}$ & Amount prepared $\mu \mathrm{g} / \mathrm{ml}$ & Amount found $\mu \mathrm{g} / \mathrm{ml}$ & $\%$ assay \\
\hline \multirow{2}{*}{$\begin{array}{l}\text { Simultaneous equation } \\
\text { method }\end{array}$} & VTL & BreoEllipta & 25 & 15 & $14.86 \pm 0.04041$ & 99.0667 \\
\hline & Fluticasone & & 100 & 60 & $59.17 \pm 0.075$ & 98.6167 \\
\hline \multirow{2}{*}{ Derivative method } & VTL & BreoEllipta & 25 & 15 & $14.91 \pm 0.0265$ & 99.40 \\
\hline & Fluticasone & & 100 & 60 & $59.43 \pm 0.0153$ & 99.05 \\
\hline
\end{tabular}

The values given in table are the average \pm standard deviation for three replicate measurements. VTL: Vilanterol, FFE: Fluticasone furoate

Table 3: Results of linearity

\begin{tabular}{|c|c|c|c|}
\hline \multicolumn{2}{|l|}{ VTL } & \multicolumn{2}{|l|}{ FFE } \\
\hline Concentration & Absorbance & Concentration & Absorbance \\
\hline 2.5 & $0.00015 \pm 1 \mathrm{E}-06$ & 10 & $0.00201 \pm 1.1547 \mathrm{E}-05$ \\
\hline 5 & $0.00073 \pm 1 \mathrm{E}-05$ & 20 & $0.00278 \pm 0.000010$ \\
\hline 7.5 & $0.00139 \pm 0.000011$ & 30 & $0.00362 \pm 0.000011$ \\
\hline 10 & $0.00198 \pm 0.000013$ & 40 & $0.00445 \pm 0.000016$ \\
\hline 12.5 & $0.00257 \pm 0.000010$ & 50 & $0.00532 \pm 0.000014$ \\
\hline 15 & $0.00321 \pm 0.000012$ & 60 & $0.00605 \pm 0.000019$ \\
\hline
\end{tabular}

The values given in table are the average \pm standard deviation for three replicate measurements. VTL: Vilanterol, FFE: Fluticasone furoate

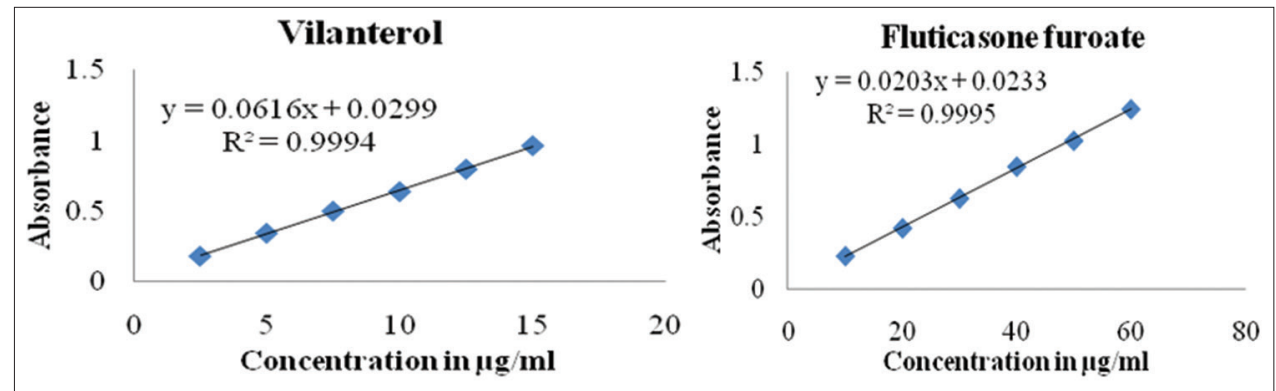

Fig. 4: Calibration graph of vilanterol and fluticasone furoate

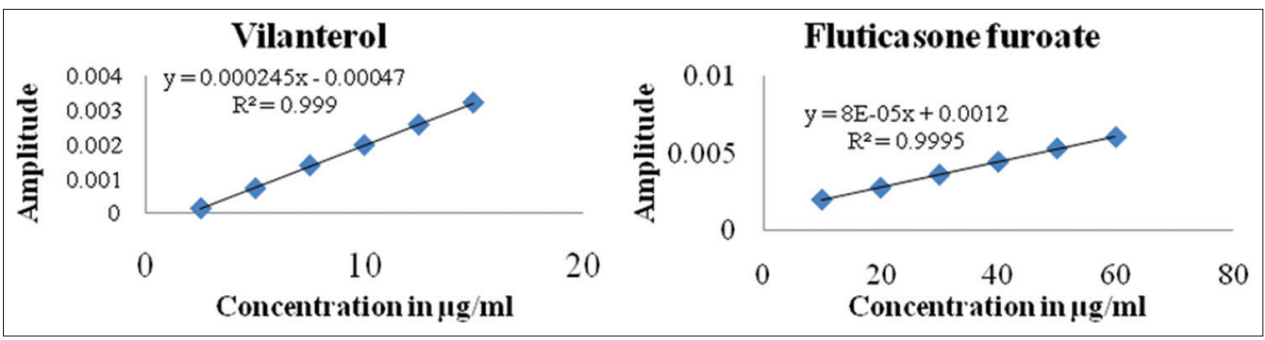

Fig. 5: Calibration graph of vilanterol and fluticasone furoate 


\section{Analysis of tabled formulation}

About 10 tablets were weighed and powdered. The quantity of powder containing the equivalent of about $25 \mu \mathrm{g} / \mathrm{ml}$ of VTL and $100 \mu \mathrm{g} / \mathrm{ml}$ of FFE was weighed accurately into $100 \mathrm{ml}$ volumetric flask. A volume of $50 \mathrm{ml}$ of the solvent was added, sonicated for 20 minutes with intermediate shaking, diluted up to the mark with the solvent and mixed, filtered through $0.22 \mu \mathrm{m}$ filter. Further, it is diluted to achieve concentrations of $15 \mu \mathrm{g} / \mathrm{ml}$ of VTL and $60 \mu \mathrm{g} / \mathrm{ml}$ of FFE. Analysis of tablet formulation BreoEllipta was carried out and the amount recovered was expressed as percentage amount of tablet claim (Table 3). The percentage recovery for VTL is 99.40 and FFE is 99.05 , respectively. The method can be successfully used for simultaneous estimation of VTL and FFE in combined dosage form.

\section{CONCLUSION}

The proposed methods ( $\mathrm{A}$ and B), i.e., simultaneous equation method and derivative method are found to be very simple and can be performed using any spectrophotometer and does not require much costly instruments. It also shows good linearity values and sensitivity. Thus, the methods are applicable for simple and economic estimation of VTL and FFE in their pharmaceutical dosage forms. Finally, it is also concluded that this was the first method developed in this combination of drugs VTL and FFE in their pharmaceutical dosage forms.

\section{REFERENCES}

1. Allen A, Schenkenberger I, Trivedi R, Cole J, Hicks W, Gul N, et al. Inhaled fluticasone furoate/vilanterol does not affect hypothalamicpituitary-adrenal axis function in adolescent and adult asthma: Randomised, double-blind, placebo-controlled study. Clin Respir J 2013;7(4):397-406.

2. Bruni FM, De Luca G, Venturoli V, Boner AL. Intranasal corticosteroids and adrenal suppression. Neuroimmunomodulation 2009;16(5):353-62.

3. Allen A, Bareille PJ, Rousell VM. Fluticasone furoate, a novel inhaled corticosteroid, demonstrates prolonged lung absorption kinetics in man compared with inhaled fluticasone propionate. Clin Pharmacokinet 2013;52(1):37-42.

4. Tamm M, Richards DH, Beghé B, Fabbri L. Inhaled corticosteroid and long-acting B2-agonist pharmacological profiles: Effective asthma therapy in practice. Respir Med 2012;106 Suppl 1:S9-19.

5. Harrell AW, Siederer SK, Bal J, Patel NH, Young GC, Felgate CC, et al. Metabolism and disposition of vilanterol, a long-acting $\beta(2)$ adrenoceptor agonist for inhalation use in humans. Drug Metab Dispos 2013;41(1):89-100.

6. Spyratos D, Sichletidis L. Umeclidinium bromide/vilanterol combination in the treatment of chronic obstructive pulmonary disease: A review. Ther Clin Risk Manag 2015;11:481-7.

7. Trivedi RK, Challa S, Patel MC, Trivedi DR, Chatrabhuji PM. A rapid, stability-indicating RP-UPLC method for the simultaneous determination of fluticasone furoate and benzalkonium chloride in a pulmonary drug product. Chem Sci Trans 2013;2(4):1184-91.

8. Nayak SC, Kulkarni PV, Bhaskar V, Chavhan V. Development and validation of UV spectrophotometric method for simultaneous estimation of doxylamine succinate and pyridoxine hydrochloride in bulk and tablet dosage form. Int J Pharm Pharm Sci 2013;5(3):390-3.

9. Kumbhar ST, Jadhav SD, Bhatia NM, Bhatia MS. Development and validation of derivative spectrophotometric method for estimation of atorvastatin calcium and amlodipine besylate in tablet dosage form. Int J Pharm Pharm Sci 2011;3(4):195-7.

10. ICH. Validation of Analytical Procedures: Text and Methodology Q2 (R1), International Conference on Harmonisation. Geneva: ICH; 2005.

11. ICH. Stability Testing: Photo Stability Testing of New Drug Substances and Products Q1B, International Conference on Harmonisation. Geneva: ICH; 2005.

12. ICH. Stability Testing of New Drug Substances and Products Q1A (R2), International Conference on Harmonisation. Geneva: ICH; 2005. 